\title{
¿Cuánto gasta el gobierno de México al expulsar a una persona extranjera indocumentada del país?
}

\author{
How much does it cost the Mexican government to expel \\ an undocumented foreigner from its territory?
}

Rodolfo Casillas R.*

ISSN IMPRESO 1870-7599 | ISSN RED CÓMPUTO 2448-7783 | 105-127

RECIBIDO: 20/05/2018 | ACEPTADO: 16/06/2018

\begin{abstract}
Resumen. El objetivo de este trabajo es analizar el gasto medio del gobierno mexicano en la devolución de un inmigrante a su lugar de origen durante el periodo 2003-2016; cabe aclarar que se trata de una aproximación deductiva. Las "Estadísticas oportunas de finanzas públicas» y los boletines estadísticos del Instituto Nacional de Migración (INM) fueron las principales fuentes de información, aunque poseen algunas limitaciones para la desagregación por rubros del gasto. Los principales resultados arrojaron que el costo por gastos de operación del INM ha tenido un papel secundario comparado con los gastos de funcionamiento. A su vez el costo promedio de devolución ha tenido importantes variaciones, con incrementos pronunciados de 2010 a 2015; y un mayor costo de devolución para las entidades federativas con una baja tradición de inmigrantes indocumentados en contraste con las de alta tradición (en específico, Chiapas, Veracruz y Tabasco).
\end{abstract}

Palabras claves: gastos de operación, migración irregular, análisis regional de la migración.

Abstract. The objective of this paper is to analyze the average expenditure by the Mexican government in the return of an immigrant to his place of origin during the period 2003-2016; it's important to clarify that this paper is a deductive approach. The "Timely Statis-tics of Public Finances» and the statistical bulletins of the National Institute of Migration (INM) were the main sources of information, although these possess some limitations for the disaggre-gation expenseper-item. The main results showed that the cost of operating expenses of the INM played a secondary role compared with operating expenses. In turn, the average cost of repayment has had significant variations, with sharp increases from 2010 to 2015, revealing a higher cost of return for the states with a lesser tradition of undocumented immigrants compared to those of high tradition (specifically, Chiapas, Veracruz and Tabasco).

Keywords: operating expenses, irregular migration, regional analysis of migration.

\footnotetext{
* Mexicano. Profesor e investigador de la Facultad Latinoamericana de Ciencias Sociales (Flacso), México. Correo-e: rodolfo.casillas@flacso.edu.mx
} 


\section{Introducción}

El título de este texto comprende una interrogante planteada por muchos y que pocos se atreven a responder. Su respuesta no es sencilla, a lo largo del artículo se expondrán las causas de su dificultad. Es imprescindible reflexionar sobre el tema por sus implicaciones en términos de política migratoria nacional, la importancia de los flujos migratorios con la gobernabilidad interna y las relaciones de México con los países vecinos involucrados.

En principio, debe conocerse el presupuesto del Instituto Nacional de Migración (INM) de México. El primer hallazgo es que la información pública sobre el monto real del presupuesto que ejerce el INM es presentada de una forma tan general que sólo permite señalamientos igualmente generales, que explican poco o sólo sirven para una crítica bastante endeble. Decir, por ejemplo, que el presupuesto del INM crece más que el de otras dependencias, o que tiene un crecimiento significativo con respecto al del año anterior, o de una administración a otra, son argumentos de fácil respuesta: aunque lo enunciado no sea cierto, más de un funcionario insistirá en que su presupuesto es mayor al de otras dependencias por necesidades distintas (mantenimiento, renovación o crecimiento de la infraestructura para brindar mejor servicio; o para atender deterioros que la administración precedente dejó pendientes; etcétera). Ya que no hay manera de cotejar porque la información utilizable está resguardada en los archivos gubernamentales bajo siete llaves (es decir, resulta inaccesible), es imposible contra argumentar. Por tanto, hay que ensayar otro método de saber para analizar.

La presentación general del presupuesto del INM no es algo que sucede solamente en esa institución, sino que es una práctica común en la administración pública mexicana: la opacidad es un distintivo que responde a distintas causas, desde prácticas administrativas objetivamente verificables, en sus anacronismos y sus avances, hasta criterios subjetivos diversos, sin negar las reticencias al escrutinio público, factibles de imponerse por vacíos de ley o interpretaciones sesgadas de la misma (véase, por ejemplo, Núñez, 2017). Entre esas razones pueden citarse al menos las siguientes: 1. Son frecuentes los desfases entre el presupuesto aprobado por el Congreso y el presupuesto ejercido por las dependencias, dados los tiempos y las prioridades de la Secretaría de Hacienda y Crédito Público (SHCP); en primera instancia, en los hechos, lo que aprueba el Congreso es un referente y no una obligación estricta para el Ejecutivo federal. Pareciera que se trata de una falta menor, o un acto que ni siquiera amerita sanción alguna, pues 
es una práctica que ocurre año tras año, independientemente de cuál sea el partido gobernante, y se desconoce si existe una sanción administrativa o la eventual inhabilitación del personal responsable. 2. De modo similiar, es frecuente la entrega a destiempo de recursos a las dependencias, lo que hace que el calendario de actividades y pagos a proveedores se concentre en los meses últimos del ejercicio fiscal; en ocasiones se efectúa una especie de pagos anticipados o concluidos cuando las actividades están por realizarse, en proceso, o con un grado mayor de atraso, de ahí que sea común que, con la intención de evitar la fecha fatídica del último día hábil de diciembre o de término de gestión, los gobernantes inauguren obras inconclusas, o que las auditorias especializadas concluyan que en los informes gubernamentales se mencionen obras públicas realizadas o concluidas, cuando no es así. ${ }^{1} 3$. Luego, al interior de las dependencias receptoras, se producen ajustes de prioridades, de calendario operativo, de transferencias de un rubro a otro, más allá de la existencia de una normatividad que las restrinja o sancione, o bien indique cómo proceder ante lo extraordinario. 4. Debe considerarse, además, el criterio discrecional para entender y registrar en un concepto algo amplio, por ejemplo, lo que se entiende por igualdad de género (desde la compra de más escobas para las mujeres encargadas de limpieza hasta cursos de capacitación en la materia para el personal de escritorio). 5. En las dependencias catalogadas como de seguridad nacional (es el caso del INM) queda un notable margen para ahí registrar lo que se quiere, o no, dar a conocer a la opinión pública bajo el argumento de que es un asunto restringido por motivos de seguridad. ${ }^{2}$ 6. En las dependencias gubernamentales suelen frasear su información de acuerdo con criterios propios, algo que es entendible por labores especializadas, pero el lenguaje puede ser más críptico si hay otras explicaciones para su uso.

De esta suerte, si la información disponible para consulta pública en medios electrónicos no es suficiente, solicitarla por medio del Instituto Nacional de Acceso a la Información (INAI) no es garantía de obtenerla, porque ante el requerimiento del INAI, la dependencia gubernamental aludida puede responder

${ }^{1}$ En el caso del INM, se recomienda consultar los informes de la Auditoría Superior de la Federación, en particular el del año 2014, en el que se presentan señalamientos graves que hasta la fecha se desconoce si fueron o no subsanados. Auditoría de Desempeño: 14-0-04K00-07-0060, GB-022; esta auditoría forma parte del Programa Anual de Auditorías para la Fiscalización Superior de la Cuenta Pública 2014, según lo dispuesto en el Plan Estratégico de la Auditoría Superior de la Federación, 2011-2017.

${ }^{2}$ Por acuerdo del Poder Ejecutivo, desde el 18 de mayo de 2005, el INM es instancia de seguridad nacional (Diario Oficial de la Federación, 2005). 
que no existe. En ese caso, la dependencia no necesariamente estaría faltando a la verdad, aunque sí la esté "torciendo»: es probable que el concepto empleado en la solicitud no corresponda al utilizado en la clasificación interna de la dependencia o que la solicitud se refiera a una fecha determinada de un periodo del cual los datos están incompletos, por lo que se notificará que se carece de la información sin especificar lo que sí se tiene, aunque sea su obligación llevar un registro anual de todo lo que implique el presupuesto público. Con un poco de buena voluntad se podría ayudar al solicitante, quien desconoce el fraseo técnico de cada dependencia pública, orientándolo acerca de cómo puede realizar las consultas en situaciones particulares.

El asunto de los registros incompletos de las dependencias de gobierno no es tema menor. Con respecto al INM, podría suponerse que los registros están completos y disponibles al menos para lo que concierne al siglo XXI, y no es así. Lo que se encuentra parece responder a criterios anacrónicos y de tiempos administrativos pasados; por ejemplo, el registro estadístico para consulta pública por medio electrónico comienza en 2003 y no desde 2001. Así, la serie estadística del INM en materia presupuestal inicia en 2003; cabe suponer, entonces, que la información de los años previos está sólo en papel y ya en "archivo muerto» (más inaccesible). Éstos y otros motivos dificultan, cuando no impiden, los análisis a profundidad de los presupuestos gubernamentales. Por ende, no es fácil pronunciarse acerca de cuánto destina el INM para cada persona extranjera indocumentada que expulsa ${ }^{3}$ a su país, o al país limítrofe por donde esa persona ingresó.

Las dificultades mencionadas, sin embargo, no impiden hacer un ejercicio deductivo e hipotético con la intención de obtener un monto aproximado. Si las autoridades correspondientes discrepan, o alguno de sus voceros (así sean oficiosos), y con información verificable señalan otra cantidad, este ejercicio habrá contribuido, con su equivocación, a tener la respuesta deseada: saber cuánto gasta el gobierno mexicano en cada evento de expulsión de una persona extranjera indocumentada.

¿Para qué sirve un ejercicio de este tipo? No hay una sola respuesta: habrá quien, desde una perspectiva eficientista, opine que es barato o es caro y piense

\footnotetext{
${ }^{3}$ De acuerdo con la jerga jurídica gubernamental, expulsar se refiere a un tipo específico de violación a la norma migratoria mexicana. En este texto no se recurre al precepto jurídico sino al hecho social de enviar fuera del país, en contra de su voluntad, a alguien que no tiene la nacionalidad local ni el permiso del gobierno nacional para ingresar, transitar o residir en territorio mexicano.
} 
en incrementar o abatir costos. Eso no puede evitarse. También habrá quien se pregunte si vale la pena destinar esos recursos en una medida que ni detiene ni desalienta al flujo migratorio en tránsito internacional por el país, y que piense que dicha inversión tiene mejores propósitos sociales si se destina a labores productivas, una manera de desalentar la emigración internacional y eventualmente fortalecer la cohesión social regional. La respuesta debe tomar en cuenta distintas dimensiones que en este artículo no se desarrollan. Se presenta, en cambio, una plataforma argumentada que facilita la reflexión en torno de lo que debe ser la política migratoria de México en uno de sus componentes principales: la migración internacional que transita por el país y sus articulaciones con otros y distintos procesos, como es la relación con Estados Unidos en particular. Desde 1994 han existido aspiraciones de integración económica con los países del norte centroamericano, de donde procede casi 95 por ciento del total del flujo indocumentado que detiene el INM. Cabe mencionar que en Centroamérica hay graves problemas ambientales ${ }^{4}$ que provocarán una gravísima crisis ambiental, la cual originará despoblamientos mayores del Istmo en decenios próximos, según indican los pronósticos más extremos. Es decir, en primera instancia, el análisis del presupuesto del INM contribuye a hablar del presente y futuro de México y de las migraciones que llegan y transitan por el país.

El texto, entonces, consta de las siguientes partes: 1. Presentación de la evolución del presupuesto del INM de 2003 a $2016^{5}$ en pesos corrientes (que se definen por los precios de bienes y servicios según su valor nominal y en el momento en que son considerados). 2. Análisis de la evolución del presupuesto del INM de 2003 a 2016 en pesos constantes con base en 2003 (que se refieren a los precios de bienes o servicios ajustados a la variación de precios de un año base). En ambos casos se verán sus fluctuaciones durante el periodo de referencia (las fluctuaciones

${ }^{4}$ Si se desea conocer un panorama ambiental de la región, pueden consultarse los estudios nacionales, en particular los del norte centroamericano: Comisión Centroamericana de Ambiente y Desarrollo (CCAD); Sistema de la Integración Centroamericana (SICA); Estrategia Regional de Cambio Climático. Documento Ejecutivo, 2010, El Salvador, Gobierno de El Salvador; Estrategia Nacional de Cambio Climático, 2013, El Salvador, Gobierno de El Salvador; Pacto Ambiental, 2016, Guatemala, Gobierno de Guatemala; Segunda Comunicación Nacional sobre Cambio Climático ante la Convención Marco de las Naciones Unidas sobre Cambio Climático, 2015, Guatemala; Instituto de Agricultura, Recursos Naturales y Ambiente (IARNA); Perfil Ambiental de Guatemala 2010-2012. Vulnerabilidad local y creciente construcción de riesgo, Universidad Rafael Landívar, Guatemala.

${ }^{5}$ Acorde con la normatividad oficial, el presupuesto de gastos para la federación se aprueba en noviembre y se publica ese mismo año en el Diario Oficial de la Federación para que entre en vigor el 1 de enero de año siguiente. 
sólo se pueden visualizar con el presupuesto en pesos constantes porque se considera la inflación, en pesos corrientes o nominales no hay comparación; la siguiente afirmación sí es válida sobre el presupuesto en precios constantes). La diferencia entre un tipo de peso y otro es importante porque la presentación de la serie histórica del presupuesto en precios constantes refleja el crecimiento porcentual real del presupuesto, lo que permitirá mostrar los crecimientos y decrecimientos reales del presupuesto del INM. 3. Ejercicio hipotético del costo de expulsión, tomando en cuenta el presupuesto y el total de la población migrante internacional, documentada e indocumentada, atendida por el INM durante el periodo de referencia. 4. Ejercicio hipotético del costo de expulsión de acuerdo con el total de la población migrante internacional secuestrada y luego liberada por la Policía Federal de 2007 a 2013. 5. Conclusiones y reflexiones finales.

\section{Presupuesto del INM 2003-2016}

La SHCP es, en el Ejecutivo federal, la que se encarga de la hacienda pública en México. Según los datos de esa dependencia, el INM recibió entre 2003 y 2016 un presupuesto anual promedio de mil 517 millones 758 mil 654 pesos para su operación (valor ajustado a precios constantes con año base 2003). La figura 1 muestra la evolución del presupuesto del INM en el periodo referido, también permite observar que en 2015 recibió el mayor presupuesto (2 mil 697 millones de pesos) y en 2003 reportó el menor monto recibido (844 millones de pesos). ว̇Tiene esto que ver con el flujo migratorio internacional?

Si bien podría asumirse que con un mayor presupuesto sería factible atender a un mayor número de migrantes o se contaría con un personal más capacitado, que realizara más y mejores operativos de protección para reducir la escandalosa cantidad de secuestros y muertes de migrantes internacionales, en realidad la ejecución y los montos totales asignados del presupuesto no tienen un origen y manejo claro. 


\section{FIGURA 1}

Presupuesto del Instituto Nacional de Migración

y su tasa de crecimiento, 2003-2016*

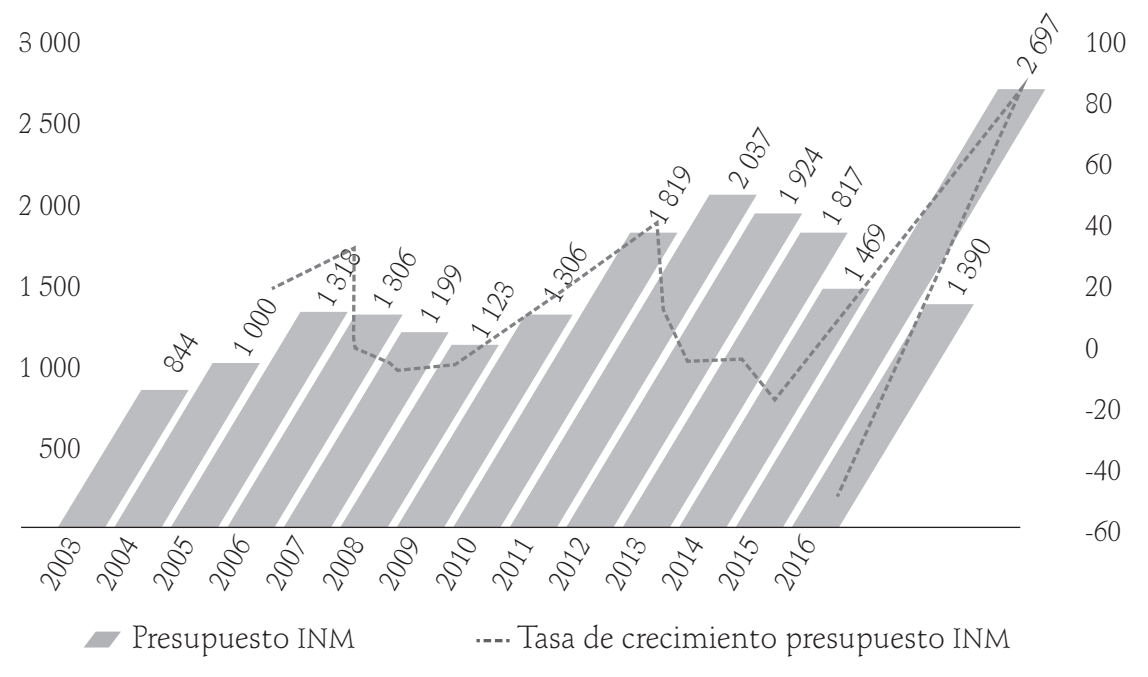

*Presupuesto en millones de pesos y pesos constantes con año base 2003.

Fuente: elaboración propia con base en SHCP, 2016a.

Un análisis de la tasa del crecimiento del presupuesto del INM indica que en algunos años se han presentado decrecimientos. Además, la figura expone las tasas de crecimiento ${ }^{6}$ ajustadas a pesos constantes. Concerniente a los descensos, se presentaron entre 2005-2008, 2011-2014 y 2015-2016. Se trata de decrementos que en algunos años alcanzan dos dígitos y representan más de 20 por ciento del presupuesto del año anterior, como ocurre en 2014 (-19.13) y 2016 (-48.46), años en que hubo recortes significativos al presupuesto federal en general. Los incrementos se registran en los años 2003, 2004, 2005, 2010 y 2015, aunque los años que reportaron un incremento notable son: 2015 (83.62), en que se atendía la «crisis humanitaria» de niñas, niños y adolescentes en Estados

${ }^{6}$ Para el cálculo de las tasas de crecimiento se tuvo en cuenta la siguiente fórmula:

Tasa de crecimiento $=\frac{\text { Presupuesto año actual }- \text { Presupuesto año pasado }}{\text { Presupuesto año pasado }}$

También es importante precisar que el ejercicio se realizó con el presupuesto a precios constantes de 2003.

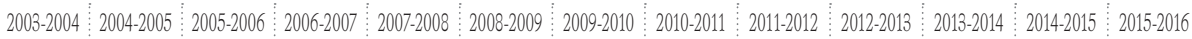

\begin{tabular}{l|l|l|l|l|l|l|l|l|l|l|l|l}
18.5 & 31.8 & -0.8 & -8.2 & -6.4 & 16.3 & 39.3 & 12.0 & -5.5 & -5.6 & -19.1 & 83.6 & -48.5
\end{tabular}


Unidos; y 2010 (39.31), 2005 (31.76) y 2004 (18.53), cuando se lograron los máximos históricos en detención de extranjeros migrantes indocumentados. Ya que no resulta clara la relación, habría que preguntarse una vez más si estos incrementos y decrementos tienen que ver con el flujo migratorio internacional.

Dado que no existe un documento del INM o del Gobierno Federal que justifique los incrementos o decrementos de dicho presupuesto, se podría plantear que éstos se deben a distintos motivos en cada caso. Por ejemplo, en 20052008, se puede suponer que hubo una combinación extraña: por un lado, la administración de Vicente Fox dio prioridad a la construcción o adecuación de espacios físicos para la detención de migrantes indocumentados, de manera que pasó de 25 estaciones migratorias al inicio de su gestión, a 52 al término de la misma; aunado a ello, en 2005 hubo el mayor número de eventos de detención de todo el periodo de análisis. Por otro lado, al tratarse de un año electoral, en 2006 ocurrieron varios cambios importantes en la Secretaría de Gobernación y en el INM que ocasionaron cierta inestabilidad en los mandos, lo que explicaría el descenso constante en las detenciones.

Existe, también, la inflación ${ }^{7}$ consignada para cada año. Al respecto, la figura 1 incluye el efecto de los niveles de inflación presentados en México durante el periodo 2003-2016, al deflactar usando el Índice Nacional de Precios al Productor (INPP). Esto permite afirmar que los incrementos del INPP no concuerdan con los niveles de incrementos del presupuesto aprobado para el INM por la SHCP. Es decir, los ajustes a los cuales ha sido sujeto el presupuesto de INM no están en función de los niveles de inflación; pero, żlo estarán en función del flujo migratorio internacional?

Antes de evaluar si los incrementos o decrementos del INM corresponden directamente con los flujos migratorios, es indispensable revisar la distribución del presupuesto con la finalidad de saber si atañe a las fluctuaciones en los gastos de operación. En ese sentido, la figura 2 expone la distribución del gasto a precios constantes del INM de acuerdo con los servicios personales y los gastos de operación.

En promedio se destina cerca de 77.90 por ciento a servicios personales (capítulo 1000 que alude a sueldos y salarios), 20.26 por ciento a gastos de operación ${ }^{8}$ y 1.84

${ }^{7}$ Los niveles de inflación presentados en este documento provienen del Índice Nacional de Precios al Consumidor.

${ }^{8}$ Los gastos de operación corresponden al capítulo de gasto 2000 , el cual clasifica los materiales y suministros con los que opera la dependencia. Para una revisión más detallada de los conceptos de gasto 
por ciento a otros gastos (capítulo 2000 que concierne a otros gastos operativos de la institución); sin embargo, no se especifica cuánto gasta el INM en operativos para detención de migrantes extranjeros indocumentados. ${ }^{9}$ Durante los años 2009, 2013 y 2015 se destinó un mayor porcentaje a los gastos de operación, aunque los servicios personales (capítulo 1000) mantienen el mayor porcentaje del presupuesto. Cabe resaltar que dentro de estas estadísticas no se precisa el costo de los operativos en campo, ni el número de personas encargadas en cada uno de ellos, por lo que el costo y gasto anual de operativos y de detenciones de extranjeros indocumentados no puede calcularse tomando en cuenta tales elementos.

\section{FIGURA 2}

Distribución porcentual del presupuesto aprobado del INM, 2003-2016*

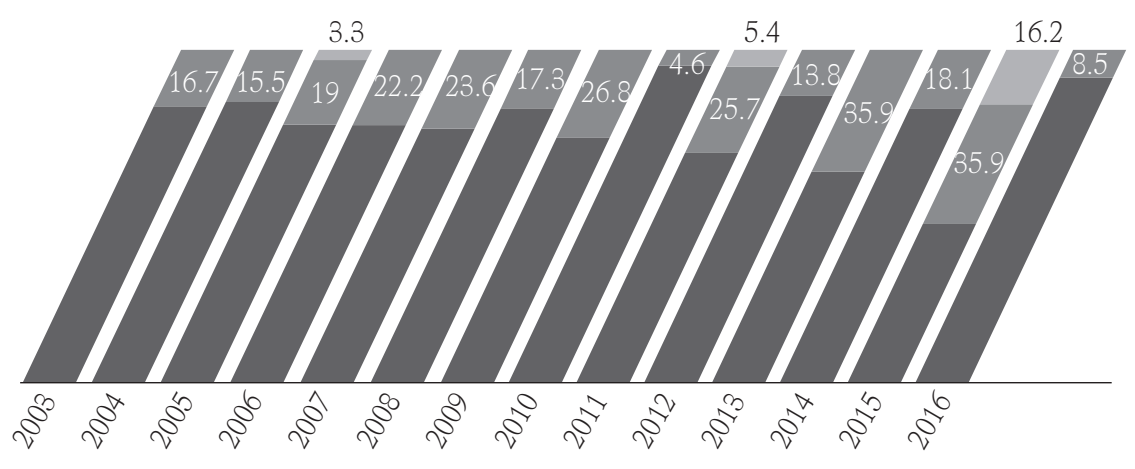

Servicios profesionales Gestión de operación Otros gastos

*Los porcentajes corresponden a la clasificación de gasto a precios constantes con año base 2003. Fuente: elaboración propia con base en SHCP, 2016a.

El análisis previo se sustenta en los informes oficiales de la SHCP, retomados de la página de «Estadísticas oportunas de las finanzas públicas» (2016a). La revisión del monto total del presupuesto ha presentado disparidades, debido a que en diversos documentos oficiales y en otros realizados por organizaciones

público, véase el Clasificador por Objeto del Gasto para la Administración Pública Federal, contenido en la Ley Federal de Presupuesto y Responsabilidad Hacendaria.

${ }^{9}$ Un dato relevante para un análisis de este apartado sería saber el número exacto de empleados del INM, así como la cantidad de operativos efectuados al año, datos que no son públicos. El autor ha escuchado a funcionarios y a exfuncionarios del INM decir que el instituto cuenta con cerca de 6 mil empleados y que en los registros internos están las cifras de los operativos. Es decir, existe información para hacer análisis precisos y verificables, pero su acceso no es público. 
independientes se advierten montos totales diferenciados. El cuadro 1 muestra el presupuesto aprobado para el INM de 2001 a 2016, publicado en «Estadísticas oportunas de las finanzas públicas» (SHCP, 2016a) y "Cuenta pública» (SHCP, 2016b), así como los datos del estudio Una mirada al presupuesto del Instituto Nacional de Migración. iDónde estuvieron sus prioridades del 2011? realizado por Fundar. ${ }^{10}$ El estudio constituye un análisis al presupuesto en un periodo menor (2005-2011) al considerado en este texto (2003-2016) y el aspecto más sobresaliente es la enorme diferencia entre las cifras recabadas por Fundar y los datos que públicamente difunde la SHCP.

\section{CUADRO 1}

Diferencias en el presupuesto asignado por la SHCP y Fundar, 2003-2016 (en pesos constantes)

\begin{tabular}{cccc} 
Año & $\begin{array}{c}\text { Presupuesto aprobado } \\
\text { publicadoen SHCP }\end{array}$ & $\begin{array}{c}\text { Cuenta pública federal } \\
\text { Programas presupuestarios* }\end{array}$ & $\begin{array}{c}\text { Presupuesto aprobado publicado } \\
\text { en el estudio de Fundar }\end{array}$ \\
\hline 2003 & 844 & 519 & $\mathrm{~N} / \mathrm{D}^{* *}$ \\
2004 & 1000 & 1320 & $\mathrm{~N} / \mathrm{D}^{* *}$ \\
2005 & 1318 & 1399 & 689 \\
2006 & 1306 & 1400 & 753 \\
2007 & 1199 & 806 & 806 \\
2008 & 1123 & 198 & 1489 \\
2009 & 1306 & $17^{* * *}$ & 2216 \\
2010 & 1819 & 1307 & 1307 \\
2011 & 2037 & 1259 & 1259 \\
2012 & 1924 & $\mathrm{~N} / \mathrm{D}^{* *}$ & $\mathrm{~N} / \mathrm{D}^{* *}$ \\
2013 & 1817 & 1254 & $\mathrm{~N} / \mathrm{D}^{* *}$ \\
2014 & 1469 & 1337 & $\mathrm{~N} / \mathrm{D}^{* *}$ \\
2015 & 2697 & 1225 & $\mathrm{~N} / \mathrm{D}^{* *}$ \\
2016 & 1390 & $\mathrm{~N} / \mathrm{D}^{* *}$ & $\mathrm{~N} / \mathrm{D}^{* *}$ \\
\hline
\end{tabular}

Nota: *Corresponde al presupuesto y gasto devengado reportado por la Subsecretaría de Egresos. Unidad de Contabilidad Gubernamental. ** No hay dato. *** La memoria estadística sólo indica que corresponde a subsidios y transferencias.

Fuente: elaboración propia con base en SHCP, 2016a y 2016b; Fundar, 2013.

${ }^{10}$ El estudio fue llevado a cabo por el programa Plan de Acción Ampliado de México en el marco de la Alianza para el Gobierno Abierto, una iniciativa multilateral que busca promover la transparencia en el gasto de gobierno. Es pertinente mencionar que 53 países firmaron dicha iniciativa. 
De acuerdo con Fundar, la información presentada es producto de diversas reuniones de trabajo entre la Secretaría de Gobernación, la Secretaría de la Función Pública y el Instituto Nacional de Migración, ${ }^{11}$ por lo cual se supondría que el monto total del presupuesto aprobado debería coincidir con los registros de la SHCP, ya que Fundar recurre a estadísticas oficiales.

Los montos totales brindados por las tres fuentes son distintos. Sólo coinciden los años 2007, 2010 y 2011. También hay coincidencias en los datos de "Cuenta pública» y los de Fundar; en cambio, no hay ninguna en los datos alusivos a las «Estadísticas oportunas de finanzas públicas» de la SHCP. خ Qué es lo que refleja estas diferencias? En primer lugar, no existe (o no se aplica) un orden compartido entre las dependencias encargadas del control del presupuesto para reportar ingresos y gastos de las diversas instituciones. En segundo, los reportes sobre la cuenta pública cambian con facilidad, por lo que se pondría en duda la aplicación de lineamientos y reglas oficiales para su difusión. En tercero, es pertinente mencionar que al buscar los datos de la cuenta pública los reportes cambian con facilidad, en cada sexenio cambia la manera de organizarlos, lo que inhibe la comparabilidad o la dificulta al extremo. Asimismo, pueden ser presentados por unidad programática, metas, indicadores, programas, tipo de gasto o temas de importancia. Son inexplicables tantas modificaciones en periodos tan cortos para organismos especializados como los financieros gubernamentales.12 Dados los cambios aludidos y las diferencias, es complicado llevar a cabo un análisis puntual de los presupuestos del INM y de cualquier dependencia.

Una aportación relevante del análisis presupuestal de Fundar es que detalla con sumo cuidado la información, por lo que se aprecian claramente las diferencias entre el presupuesto aprobado y ejercido (cuadro 2). El incremento se debe a dos ingresos extraordinarios: 1. Ingresos provenientes del pago de derechos migratorios, multas, sanciones, entre otros. 2. Aportaciones internacionales. Fundar advierte que el INM recibió aportaciones de la Iniciativa Mérida; sin embargo, aclara que las aportaciones de esa iniciativa no se incluyen en el monto total del presupuesto ejercido porque son en especie. Entonces, la pregunta es: żson los ingresos provenientes del pago de derechos lo que hace que cambien los montos presupuestarios?

${ }^{11}$ La información de Fundar proviene también del Gobierno Federal, por lo que no deberían existir diferencias entre los montos totales del presupuesto.

${ }^{12}$ Para mayor detalle, consúltese SHCP, 2016 b. 


\section{CUADRO 2}

Presupuesto aprobado y ejercido por el INM, según Fundar, 2005-2011

\begin{tabular}{ccccc} 
Año & $\begin{array}{c}\text { Presupuesto } \\
\text { aprobado }\end{array}$ & $\begin{array}{c}\text { Presupuesto } \\
\text { ejercido }\end{array}$ & Diferencia & $\begin{array}{c}\text { \% diferencia con } \\
\text { respecto al aprobado }\end{array}$ \\
\hline 2005 & 6.89 & 15.15 & 8.27 & 120 \\
2006 & 7.53 & 13.95 & 6.02 & 80 \\
2007 & 8.06 & 12.50 & 4.44 & 55 \\
2008 & 14.89 & 16.06 & 1.17 & 8 \\
2009 & 12.16 & 18.88 & 6.72 & 55 \\
2010 & 13.07 & 20.65 & 7.58 & 58 \\
2011 & 12.59 & 21.06 & 8.46 & 67 \\
\hline
\end{tabular}

En miles de millones de pesos a precios constantes con base en 2003.

Fuente: Fundar, 2013

La revisión de las dos fuentes estadísticas oficiales no indica una aportación de este tipo de concepto. Aunque no hay manera de saber el desglose de esos ingresos extraordinarios, se pueden hacer algunas deducciones. Los ingresos por pago de derechos, multas y sanciones, entre otros, es algo que ocurre todos los años, con la modalidad de que el INM tiene que enviarlos a las arcas gubernamentales y luego de ahí se le reembolsa una parte (unos cuantos centavos por cada peso). Pese a que es una práctica que se repite cada año, es probable que los reembolsos ocurran con frecuencia a destiempo, según suele proceder la SHCP en general. Por tanto, cabe pensar que son las aportaciones internacionales las que proveen el grueso de los ingresos extraordinarios. ¿Quiénes pueden hacer ese aporte extraordinario y de tan significativo monto?

Salvo Estados Unidos, difícilmente otros países lo harán. En cuanto a los países centroamericanos, de donde procede el grueso de los migrantes indocumentados detenidos por el INM, sus finanzas son tan frágiles que necesitan apoyos diversos para que no colapsen, por lo que les sería muy complicado enviar recursos para ayudar a mejorar el trato a sus nacionales en las estaciones migratorias mexicanas. Tampoco pueden hacerlo Ecuador y Cuba, cuyos nacionales ocupan un lugar preponderante dentro de las primeras nacionalidades de indocumentados detenidos en México, pues no tienen recursos financieros. No lo harán los países asiáticos y africanos de donde proceden otros flujos de migrantes indocumentados de paso, ni los países europeos. Por la razón que sea, a ninguno 
de estos países les interesa hacer tal financiamiento. En consecuencia, quedan algunas agencias internacionales, como la Organización Internacional para las Migraciones (OIM), que ofrece actividades copatrocinadas, como cursos de capacitación y realización de eventos, y proporciona efectivo para un selectivo traslado de migrantes indocumentados detenidos por el INM procedentes de Asia y África; no obstante, en el mejor de los casos los montos podrán llegar a 50 mil dólares en un año. Así, la interrogante continúa: ว̇de dónde sale esos millones que le fueron informados a Fundar? Una incógnita preocupante, dado que el mundo anda escaso de donantes y filántropos, en especial para genuinas causas humanitarias.

En algunos años las aportaciones corresponden a más de 50 por ciento del presupuesto asignado, ${ }^{13}$ pero no hay forma de saber quién hace la aportación y a qué partidas conciernen, dado que no se encontraron estadísticas referentes a este componente (INM, 2016) en las páginas del INM, la SHCP o la Secretaría de Gobernación. La suspicacia hace pensar que dichos montos van con «etiqueta» para asuntos específicos, pero no hay información al respecto. Se trata de una opacidad mayor y adicional a las otras previamente aludidas.

Otro aspecto fundamental del estudio es la confirmación del gasto en el capítulo 1000: "Lo único que garantiza el presupuesto aprobado son los sueldos y salarios de personas que trabajan en el INM (...) es decir, donde se canalizó más de 75 por ciento del presupuesto» (Fundar, 2013:13). En otras palabras, se utilizan pocos recursos para la atención de la población migrante y la protección de sus derechos, así como para los operativos de detención de migrantes indocumentados.

La figura 3 muestra la relación entre la tasa de crecimiento del presupuesto del INM y las tasas de crecimiento de migrantes detenidos en las estaciones migratorias. Si bien los comportamientos de dichas figuras no son similares, el incremento o decremento del presupuesto no concuerda con los incrementos o decrementos de los eventos de detenidos en las estaciones migratorias. Si se pensara que al incremento del presupuesto correspondería un incremento en la detención de los flujos migratorios indocumentados, los datos estadísticos no lo respaldarían.

En efecto, la justificación de los incrementos o decrementos no parece relacionarse directamente con el mayor o menor número de detenciones del año

${ }^{13}$ El análisis de Fundar no se presenta en precios constantes, por lo que no se aprecian los incrementos o decrementos reales del presupuesto ejercido. 
precedente, por lo que no se puede deducir en qué medida influye la cantidad de detenciones en la asignación del presupuesto. La inflación y el número de detenciones no son elementos primordiales que afecten los incrementos o decrementos del presupuesto asignado.

\section{FIGURA 3}

Tasa de crecimiento presupuestal y de eventos de expulsión de migrantes indocumentados por parte del INM, 2003-2016

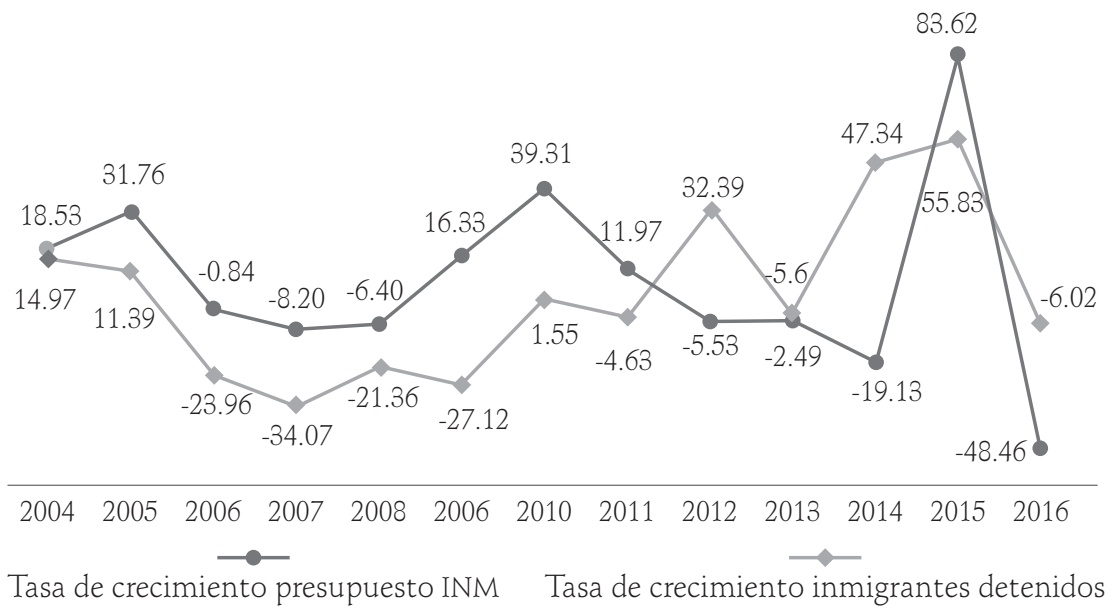

Fuente: elaboración propia con base en SHCP, 2016a; INM, 2003-2016.

Los mapas 1 y 2 muestran la cifra de secuestros de migrantes por entidad federativa y eventos de extranjeros indocumentados detenidos por el INM, respectivamente. Chiapas, Veracruz, Tabasco y Oaxaca son las entidades que registran las cifras más altas en ambos rubros. No obstante, en Tamaulipas la prensa ha documentado el mayor número de secuestros y muertes violentas de migrantes.

De acuerdo con lo anterior, las entidades con el menor número de secuestros y rescates efectuados por la Policía Federal fueron Colima, Morelos y Baja California Sur; y los que reportaron la menor cantidad de migrantes detenidos en estaciones migratorias fueron Colima, Baja California Sur y Michoacán. 


\section{MAPA 1}

Total de migrantes internacionales secuestrados y rescatados por la Policía Federal, 2007-2014

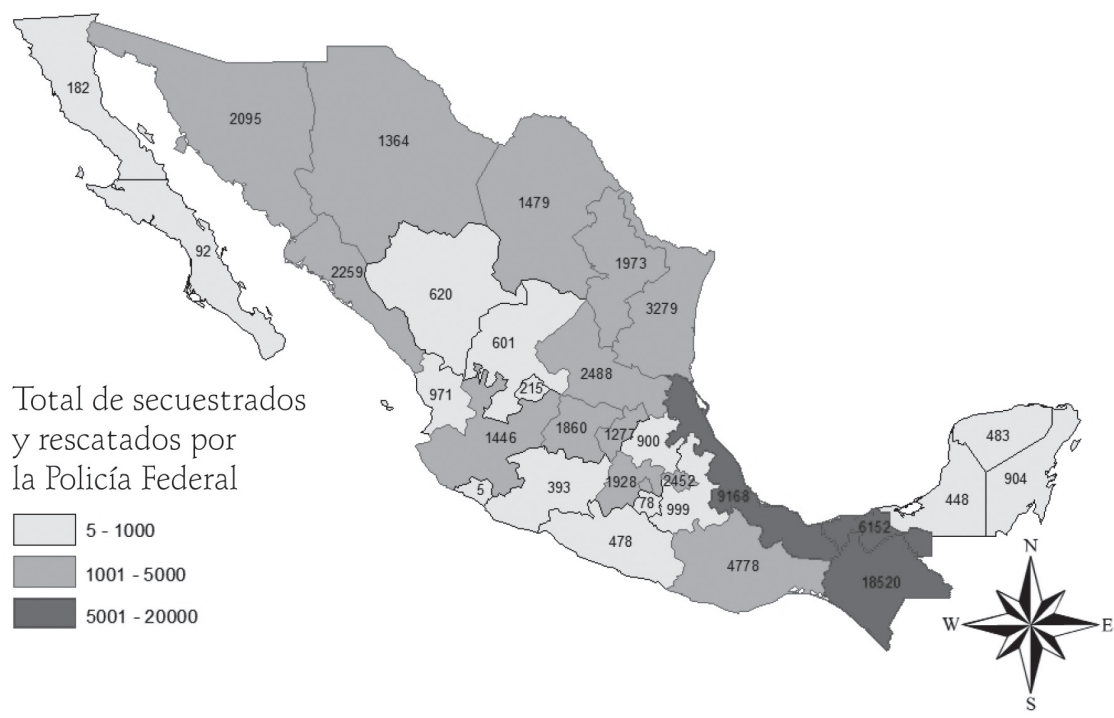

\section{MAPA 2}

Total de migrantes internacionales detenidos por el INM, 2007-2014

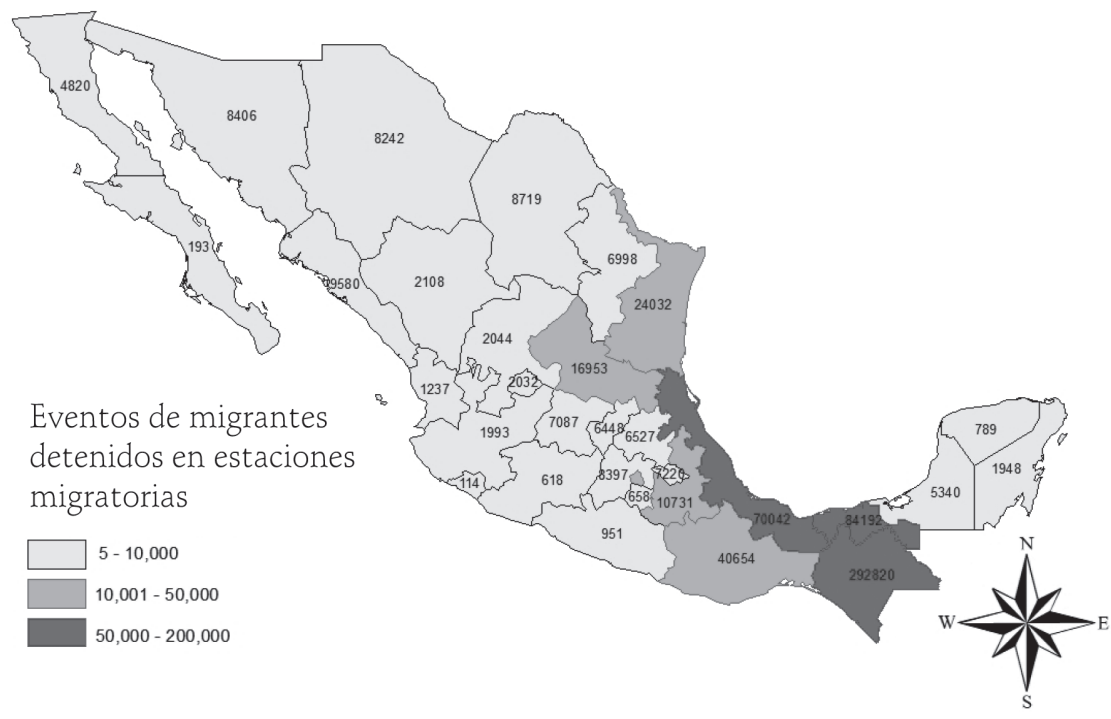


La figura 4 enseña los eventos de migrantes devueltos por el INM anualmente. De 2003 a 2016 se registró un total de 1 millón 739 mil de devoluciones, en promedio 124 mil 250 migrantes por año. Durante 2004, 2005 y 2015 se llevó a cabo la mayor cantidad de devoluciones, años terribles para los migrantes, pues se conjugaron más detenciones con cifras altas de secuestrados (véase INM, para los años citados y Rivas, 2014). No obstante, entre 2008 y 2013, los inmigrantes devueltos en cada año no superaron las 100 mil personas, ello a causa de un conjunto de razones diversas abordadas en otro texto (Casillas, 2012).

\section{FIGURA 4}

Total de eventos de migrantes devueltos por el INM de México

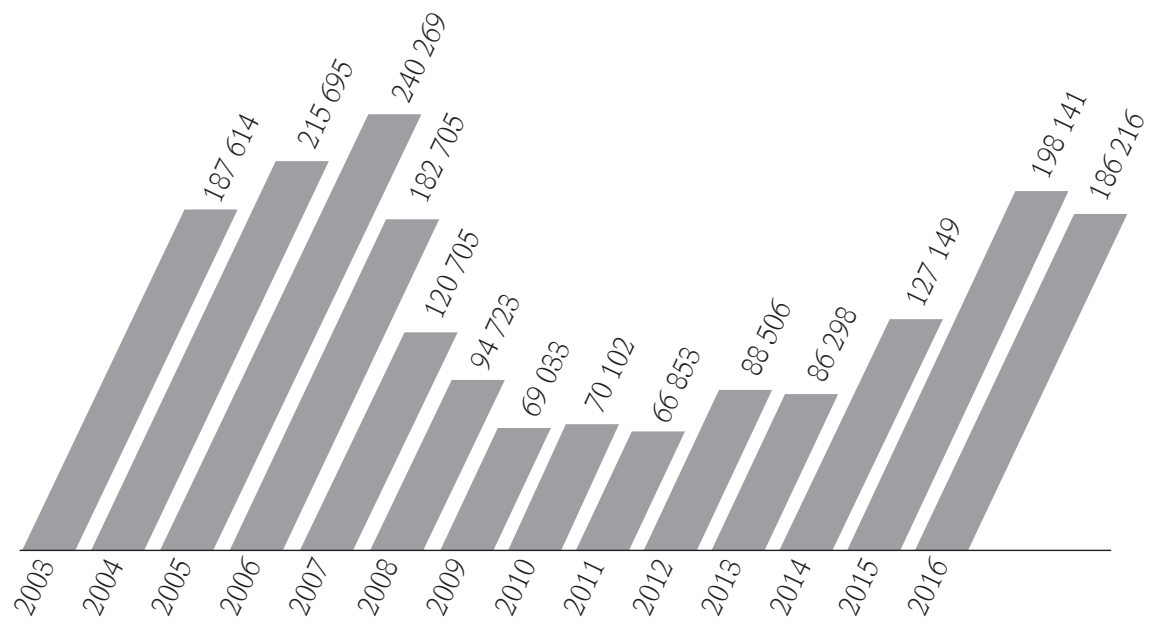

Fuente: elaboración propia con base en SHCP, 2016a; INM, 2003-2016.

\section{Análisis de gasto de migrantes por el INM, 2003-2014}

De acuerdo con los datos de INM y de la SHCP, el presupuesto de gasto del INM ha cambiado considerablemente. Algunos años han notificado pérdidas de más de 40 por ciento, lo que ha provocado que el costo de detenciones sea variable en el tiempo. Las variaciones en el presupuesto aprobado ${ }^{14}$ hacen factible realizar

${ }^{14}$ El ejercicio del costo de las detenciones es hipotético, dado que no se cuenta con la información completa del presupuesto aprobado y ejercido por el INM. En el documento Una mirada al Instituto Nacional 
un ejercicio sobre los gastos que el INM destina a los flujos de migrantes - un ejercicio hipotético, cabe recordar. El costo de detención permite vislumbrar que el presupuesto asignado es insuficiente para llevar a cabo una asistencia adecuada que garantice los derechos humanos de la población.

Antes de la descripción de los datos es necesario atender algunas consideraciones metodológicas:

1. Para realizar el análisis se recurre al presupuesto aprobado por la SHCP (2016a).

2. El costo por evento proviene de dividir el presupuesto aprobado entre el número de eventos de detenciones de migrantes indocumentados. No se utiliza el presupuesto ejercido porque éste no se encuentra en las páginas de la SHCP y del INM.

3. Además, en la realización de este cociente se toma en cuenta la proporción del presupuesto del INM destinado a gastos de operación. Constituye un valor más real, dado que se descontarían gastos usados en el pago de salarios a los trabajadores del INM.

4. Es un promedio, es decir: Costo total = Presupuesto aprobado para gastos de operación / Número de eventos de extranjeros.

5. No se incluye la entrada de extranjeros por vía aérea.

6. El presupuesto aprobado para gastos de operación se presenta a precios de 2003.

El cuadro 3 indica el costo promedio por persona de las detenciones de migrantes del INM, el cual fue de 2 mil 519 pesos a precios constantes del año 2003 durante el periodo de estudio. También permite observar que en 2011 y 2013 se registró el mayor costo por extranjero devuelto. Los años con costos menores fueron 2003 y 2004, y para 2007 se acercó al costo promedio del periodo de estudio.

de Migración, de Fundar (2013) se advierte que el presupuesto ejercido se modifica hasta en más de 120 por ciento debido a aportaciones gubernamentales extraordinarias, aportaciones internacionales u otros conceptos. 


\section{CUADRO 3}

Costo de eventos de extranjeros indocumentados expulsados por el INM, 2003-2016

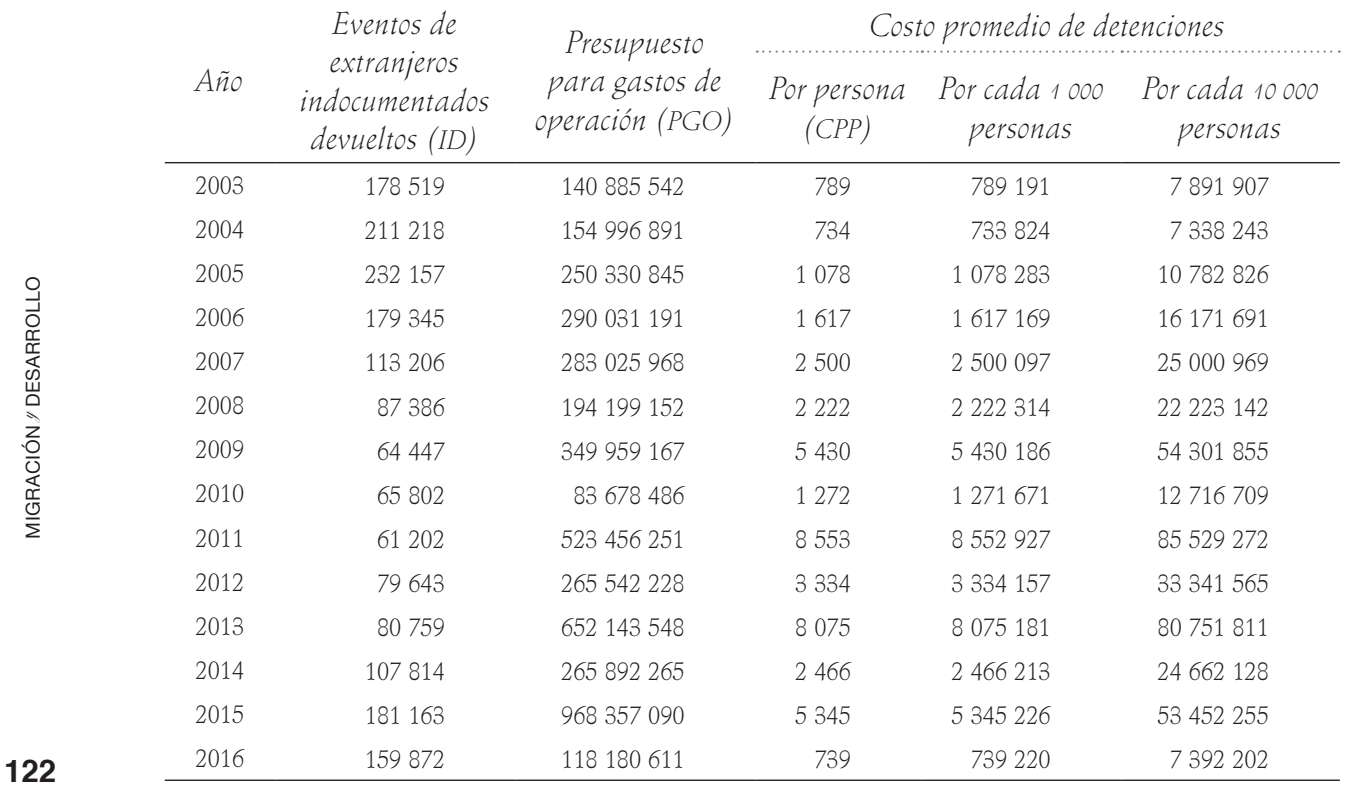

Fuente: elaboración propia con base en SHCP, 2016a; INM, 2003-2016.

Además de documentar la entrada y la salida de extranjeros de forma legal, el INM cumple con otras funciones, lo que implica que habrá variaciones en el costo promedio de devolución de un inmigrante en función de la distribución de los gastos operativos, incluyendo gastos por documentación.

Otro ejercicio deductivo consiste en desagregar el costo promedio según entidad federativa, pese a que no se conoce la distribución del presupuesto por las distintas unidades regionales del INM. Como lo muestra el cuadro 2, existe un corredor de migrantes detenidos más pronunciado en Chiapas, Tabasco, Veracruz (grupo de primer nivel), y en un segundo grupo se encuentran Oaxaca, Puebla, Ciudad de México, San Luis Potosí y Tamaulipas. Con dicha información se estima el costo promedio según grupo de mayor o menor devolución de los migrantes.

El cuadro 4 presenta los gastos estimados en promedio por devolución de un grupo de inmigrantes de acuerdo con cada nivel de entidades federativas, con base en el costo promedio por persona calculado anualmente en el cuadro 3. Los 
resultados muestran claramente un predominio de los gastos en las entidades del nivel I (Chiapas, Tabasco y Veracruz): aproximadamente 2 mil 965 millones de pesos (con base en 2003) durante el periodo 2003-2016. Las cifras de los niveles II y III son de tres a cuatro veces menores. El grupo que concentra a la mayoría de entidades gastó 854 millones de pesos; en el del nivel II los gastos fueron de 722 millones de pesos aproximadamente.

\section{CUADRO 4}

Costo de eventos de extranjeros indocumentados expulsados por el INM según niveles de detención de las entidades federativas, 2003-2014

\begin{tabular}{|c|c|c|c|c|c|c|c|c|c|}
\hline Año & 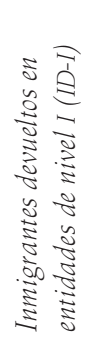 & 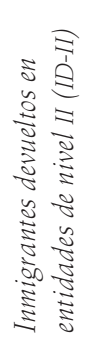 & 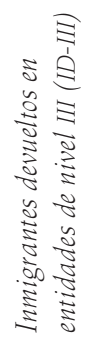 & 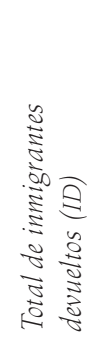 & 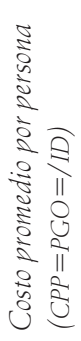 & 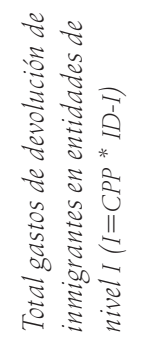 & 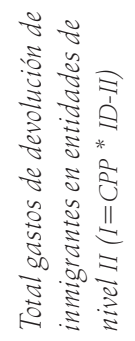 & 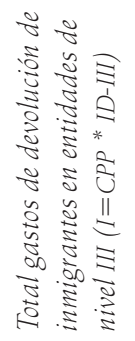 & 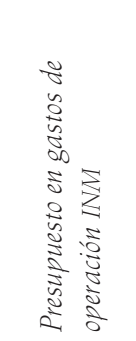 \\
\hline 2003 & 104734 & 47116 & 26669 & 178519 & 789 & 82655103 & 37183511 & 21046928 & 140885542 \\
\hline 2004 & 139572 & 32690 & 38956 & 211218 & 734 & 102421319 & 23988715 & 28586858 & 154996891 \\
\hline 2005 & 148044 & 40416 & 43697 & 232157 & 1078 & 159633264 & 43579868 & 47117713 & 250330845 \\
\hline 2006 & 126014 & 22389 & 30942 & 179345 & 1617 & 203785946 & 36206799 & 50038446 & 290031191 \\
\hline 2007 & 80068 & 17118 & 16020 & 113206 & 2500 & 200177757 & 42796658 & 40051552 & 283025968 \\
\hline 2008 & 58848 & 17173 & 11365 & 87386 & 2222 & 130778748 & 38163802 & 25256601 & 194199152 \\
\hline 2009 & 16919 & 8213 & 39315 & 64447 & 5430 & 91873309 & 44598114 & 213487744 & 349959167 \\
\hline 2010 & 41002 & 10678 & 14122 & 65802 & 1272 & 52141048 & 13578901 & 17958536 & 83678486 \\
\hline 2011 & 37584 & 11036 & 12582 & 61202 & 8553 & 321453216 & 94390105 & 107612930 & 523456251 \\
\hline 2012 & 51933 & 13037 & 14673 & 79643 & 3334 & 173152751 & 43467399 & 48922079 & 265542228 \\
\hline 2013 & 56250 & 13115 & 11394 & 80759 & 8075 & 454228935 & 105906000 & 92008613 & 652143548 \\
\hline 2014 & 75618 & 17751 & 14445 & 107814 & 2466 & 186490078 & 43777743 & 35624444 & 265892265 \\
\hline 2015 & 136317 & 24460 & 20386 & 181163 & 5345 & 728645107 & 130744216 & 108967767 & 968357090 \\
\hline 2016 & 104608 & 32042 & 23222 & 159872 & 739 & 77328346 & 23686093 & 17166171 & 118180611 \\
\hline tales & & 7234 & & & 2519 & 64928 & 22067925 & B 846383 & 4540679236 \\
\hline
\end{tabular}

Fuente: elaboración propia con base en SHCP, 2016a; INM, 2003-2016.

Finalmente, con la información de los cuadros 3 y 4, se estimó el costo promedio de devolución de un inmigrante de 2003 a 2016 para los tres niveles de 
entidades federativas. Cabe aclarar que el cálculo está afectado por el supuesto de que todos los gastos en operación del INM se destinan a los trámites de devolución. Los resultados exhiben que las entidades con menor número de inmigrantes detenidos en el periodo de estudio (nivel III) gastaron en promedio 100 o 300 pesos más en comparación con el resto ( 2 mil 687 pesos). En tanto, el gasto promedio de las entidades del nivel I y el total nacional es similar (2 mil 518 pesos).

\section{FIGURA 5}

Costo promedio de devolución de un extranjero indocumentado por parte del INM y niveles de detención por entidades federativas (precios constantes 2003)

\section{4}

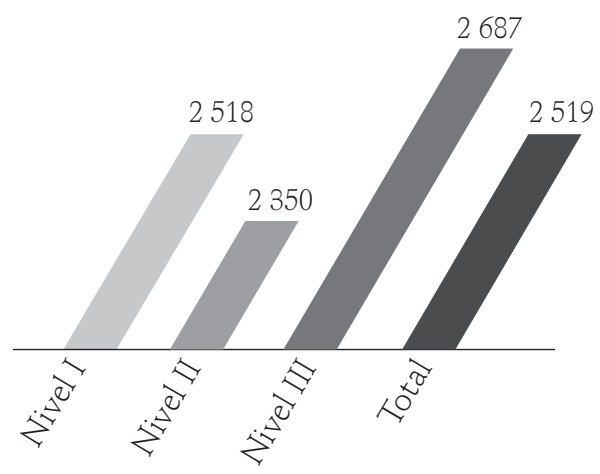

Fuente: elaboración propia con base en SHCP, 2016a; INM, 2003-2016.

\section{Conclusiones y reflexiones}

1. Sería deseable que las autoridades federales correspondientes liberaran la información completa, a partir de 2001, a efecto de tener la serie estadística presupuestal desde el inicio del siglo XXI.

2. Asimismo, sería pertinente que la información estuviese completa, al menos del presupuesto ejercido, y con claridad en los rubros. Es entendible que a lo largo del año ocurran imprevistos que lleven a hacer ajustes sobre la marcha, pero, żpor qué existe la opacidad financiera cuando hay elementos para explicar las adecuaciones?

3. La opacidad en el ejercicio del presupuesto, incluso en los «ingresos extraordinarios», cuyos montos son notablemente altos, generan preocupación. 
Por su parte, la nómina absorbe, como sucede en numerosas oficinas públicas, ingentes recursos del presupuesto ordinario; pareciera que los «ingresos extraordinarios» dejan un amplio margen para la realización de operativos vinculados con la población extranjera indocumentada que transita por el país, con gran discrecionalidad. Dados los reiterados señalamientos de corrupción, esos elevados montos extraordinarios y su manejo «flexible» alimentan la suspicacia.

4. Lo anterior no implica que el manejo del presupuesto ordinario esté libre de duda. En una administración del periodo estudiado mucho se comentó, de manera extraoficial, acerca del manejo discrecional en viáticos, de la caja chica, del personal en delegaciones, del número «inflado» de indocumentados detenidos con la intención de reportar más gastos en alimentos, traslados, renta de vehículos, personal comisionado, etcétera. En esos momentos el instituto no enmendó a su personal, aunque eventualmente hubo un cambio de adscripción delegacional; al tratarse de una medida aislada, se terminó por favorecer la extensión de las prácticas ilícitas.

5. En el presupuesto no se refleja la construcción o adecuación de 25 estaciones migratorias durante la administración de Vicente Fox, un crecimiento de 100 por ciento en un sexenio, lo que no necesariamente significó un mayor volumen de detenciones; por el contrario, la estadística oficial reporta decrementos importantes en el sexenio siguiente. La información disponible para el segundo trienio del mandato de Fox indica un crecimiento bajo, como suele suceder con la obra pública en general, máxime que pasar de 25 a 52 estaciones migratorias implicó también otros gastos como contratación de personal, equipamiento, etcétera.

6. Durante 2014 y 2015 hubo un significativo incremento del presupuesto del INM, quizá debido a la situación extraordinaria que generó en particular la llamada «crisis humanitaria» de niñas, niños y adolescentes señalada por el entonces presidente Barack Obama en operativos, trasladados de personal de otras latitudes hacia el norte de Chiapas, buena parte de Oaxaca y Veracruz, gastos de estadía, renta de más vehículos, etcétera.

7. Eventualmente, hubo gastos extraordinarios por el virus A(H1N1) en 2010 en estaciones migratorias y tuvieron lugar varios operativos, lo que ayudaría a entender que en ese año el rubro de nómina haya sido el más alto del periodo analizado.

8. A final de cuentas, 2 mil 500 pesos como gasto promedio por extranjero indocumentado expulsado de México, żes poco o es mucho? Si se toma en cuenta 
ese costo, al convertirlo en dólares y compararlo con una expulsión desde Estados Unidos, se confirma una apreciación con sustento verificable: es más barato para las autoridades migratorias detener y devolver en el sur, por la cercanía con el origen territorial de más de 95 por ciento de los extranjeros indocumentados, y mientras más al sur sea, más barata es la expulsión. Dado que Guatemala y Belice carecen de infraestructura, personal, régimen institucional confiable (más allá de prácticas de dudosa validez en el manejo de recursos públicos) para detener el flujo indocumentado, resulta como única opción viable concentrar los operativos de detección, detención y devolución en México en general, en especial en el sur-sur mexicano, con base en un objetivo: el análisis económico del ejercicio presupuestal. Por alguna racionalidad financiera en el sur, los gobiernos de México edificaron más de 20 estaciones migratorias y en ellas las administraciones panistas y priistas dispusieron equipo e infraestructura suficientes para llevar un registro estadístico y biométrico de todos los migrantes extranjeros detenidos por indocumentados o atendidos por algún trámite ocasionado por el ingreso, la estadía o el paso legal. El asunto es, żla política migratoria de México se basa sólo en la variable económica y en el costo promedio por cada extranjero expulsado del país?

9. Ese registro, que el gobierno de México comparte con las autoridades migratorias de Estados Unidos (ICE, por sus siglas en inglés), bajo la cobertura de la Iniciativa Mérida, es muestra fehaciente de que esa colaboración no calma la paranoia estadounidense de posibles terroristas y tampoco le granjea simpatías al actual gobierno mexicano entre los partidarios de un buen trato hacia los migrantes extranjeros. En otras palabras, la colaboración que México da no satisface a Estados Unidos ni a sectores sociales mexicanos, que de distinta manera recibe críticas de ambos. Por estas razones, ìno sería motivo para replantear qué y cómo hacer una política migratoria hacia los flujos migratorios que transitan por México que quite o aligere cargas innecesarias y se encamine a mejores resultados?

\section{Referencias}

Casillas, Rodolfo (2012), «La construcción del dato oficial y la realidad institucional: disminución del flujo indocumentado en los registros del INM», Migración y Desarrollo, 10(19), pp. 33-60. 
Diario Oficial de la Federación (18 de mayo de 2005), "Acuerdo del Poder Ejecutivo para que el Instituto Nacional de Migración sea una instancia de seguridad nacional».

Fundar Centro de Análisis e Investigación (2013), Una mirada al presupuesto del Instituto Nacional de Migración. iDónde estuvieron sus prioridades del 2011?, México, Fundar.

Instituto Nacional de Migración (INM) (2016), «Multas y sanciones», en http://www. inm.gob.mx/gobmx/word/index.php/multas-y-sanciones/

Núñez González, Leonardo (2017), iY dónde quedó la bolita? Presupuesto de Egresos ficticio. Cómo el gobierno hace lo que quiere con nuestro dinero, México, Aguilar.

Rivas Rodríguez, Francisco Javier (coord.) (2014), Análisis Integral del Secuestro en México. Cómo entender esta problemática, México, Observatorio Nacional Ciudadano de seguridad, justicia y legalidad.

Secretaría de Hacienda y Crédito Público (SHCP) (2016a), «Estadísticas Oportunas de Finanzas Públicas», México, SHCP, en http://www.shcp.gob.mx/POLitiCAFinAnCieRA/ FINANZASPUBLICAS/Estadisticas_Oportunas_Finanzas_Publicas/Paginas/unica2. aspx

(2016b), «Cuenta pública», México, SHCP, en http://cuentapublica.hacienda.gob.mx 